\title{
Climate and nomadic migration in a nonlinear world: evidence of the Historical China
}

\author{
Olivier DAMETTE \\ BETA, UMR CNRS 7522, University of Lorraine, Climate Economic Chair Paris Dauphine \\ Stephane GOUTTE \\ CEMOTEV, UVSQ, Paris-Saclay, France. \\ Qing PEI \\ Department of Social Sciences, The Education University of Hong Kong
}

May 30, 2020

\begin{abstract}
This paper deals with climate change and nomadic migration relationships at a long term and wide geographical scale using a statistical approach in the vein of Bai and Kung (2011). More precisely, it presents a reassessment of these relationships in a nonlinear world using threshold regressions, time varying-copula and nonlinear causality tests. The large amount of historical records in China enables us to re-interpret the link between climate and historical social dynamics (Hsiang et al., 2013) through different regimes of temperatures and precipitations.
\end{abstract}

Keywords: Climate change, Nomadic migration, Conflicts, Historical China, Threshold Regression, Non linearity, Copula, Cau JEL classification: C22, C53, E32, E33, F00, Q00

Corresponding authors: Damette Olivier; olivier.damette@univ-lorraine.fr; Qing Pei; qingpei@eduhk.hk. This reasearch has been supported by ARIANE FEDER research fund NiñoMACRO project and University of Lorraine (LUE, Widen Horizons grant) and Early Career Scheme project funded by the Research Grants Council of Hong Kong (ref. no. 28300717). 


\section{Introduction}

Considerable academic attention has been given to climate change to explain the nomadic migration worldwide, which deeply shaped human history in the past (Di Cosmo, 2002; Halsall, 2007; Imber, 2002). Case-based method (Büntgen and Di Cosmo, 2016) and statistical approach (Bai and Kung, 2011) have been extensively chosen by current scholars to empirically examine the historical association between climate change and nomadic migration. In particular, China has accumulated ample ancient archives on nomadic migration because the nomads' movement frequently threatened territorial security and farming livelihoods (Ge, Wu, Cao, 1997). The large amount of historical records enables the statistical analysis on nomadic migration under climate change at a long term and wide geographical scale to share the implications to the globe. This kind of quantitative practice is emerging as a recent trend to re-interpret historical social dynamics (Hsiang et al., 2013).

Existing macroscale studies, such as by Fang and Liu (1992) and Pei and Zhang (2014), have contributed to the empirical understanding on the nomadic migration under the effects of climate change. The specific roles of temperature and precipitation have been examined using different statistical tools, including correlation, multiple regression, and Granger (1969) causality analysis. Nomadic migration increased during periods of cooling or drought in the past. This phenomenon outlines a negative correlation between the migratory movements of nomads and climatic factors, specifically temperature and precipitation. However, regression and causality studies further examine that only precipitation, and therefore here mainly periods of droughts, has been the cause of increased migratory movements to the North and South of China that seem to have further caused, in Granger's sense, the evolution of interpersonal conflicts over time. These studies have not only developed the knowledge on climate change-nomadic migration linkage but also proven the feasibility of social archives from historical China for the robust analysis of cliometric type.

Although the association between climate change and nomadic migration has been previously explored in the aforementioned works, the research methodologies employed have obvious limitations. First, these works have mainly relied on linear approaches. However, previous linear works have failed to consider the holistic effects of climate change, because the effects of climate change on human society present a nonlinear or abrupt pattern (McNeall et al., 2011). Therefore, nonlinear and threshold models should be selected. Second, if the nonlinear patterns of climatic effects are considered, then migration, as the resilience of nomadic society to climate change, should be re-evaluated accordingly. Specifically, nomadic migration should be examined under different levels of climate change if using nonlinear methods, rather than treating nomadic migration as a whole in previous practices. The migration of nomads, particularly southward migration, risks the conflicts with farmers living in the South. The re-interpretation on nomadic migration can help us understand the nomadic resilience across different dynasties, political regimes, and exogenous factors over such long periods. Therefore, nonlinear and threshold models can bring new 
knowledge on the roles of climate change and nomadic migration in the climate change-nomadic migration linkage.

The development of theories requires innovation in ideas and methodologies (Rosenberg, 2008). In this study, we aim to develop the econometric framework to consider nonlinear patterns for the first time. In a very long historical period of over 2,000 years, different climatic and migratory regimes may have followed one another with more or less tenuous links over time. That's why we use threshold models, nonlinearity causality tests and time varying copula to reassess the links between climate and migration. The large amount of historical records in China enables us to re-interpret the link between climate and historical social dynamics (Hsiang et al., 2013) through different regimes of temperatures and precipitations.

Section 2 presents the dataset and the threshold model used to estimate nonlinear relationships between climatic and migratory regimes. Section 3 outlines the results of the threshold model regression and causality - both linear and nonlinear - analysis. Section 4 checks the robustness test of the previous results by applying a recent time-varying copula analysis. Section 5 presents a discussion of the results. Finally, Section 6 concludes the paper.

\section{Data and Methodology}

\subsection{Data}

The dataset we use is similar to that previously utilized by Pei et al. (2018), Pei, Lee, and Zhang (2017), and Pei and Zhang (2014). This dataset consists of a set of time series of three main variables, namely, migration flows, precipitation anomalies, and temperature anomalies, covering the period from $220 \mathrm{BC}$ to AD1910.

Our climate dataset consists of two variables: temperature and precipitation anomaly variables. Reconstructions of historical climate data have the advantage of covering the whole of China over the period but are not actual records for each year, the availability of which appears to be almost impossible. These series of temperature anomalies have been calculated from the data produced by Yang et al. (2002) that consist of temperatures reconstructed from several origins and proxies: glaciers, sedimentation of lakes, tree rings, and historical documents.

Pei and Zhang (2014) explained that other reconstruction temperatures for China are similar to those of Yi et al. (2012) and Tan et al. (2003), but they do not cover the entire country geographically. These series of temperature anomalies are already used elsewhere by Pei and Zhang (2014) and Lee and Zhang (2013) in specialized international journals. The quality of the aforementioned series is accepted by the international scientific community to trace climatic fluctuations over time.

The used precipitation data are those produced by Pei and Zhang (2014) and have been reconstructed from a synthesis carried out with 21 document- 
based series. These data have been subjected to checks from other sources, at very low frequency (one point per hundred years) for example, to attest to their reliability. Documentary data presents special advantage on time preciseness if comparing with natural proxies, such as tree rings or cave speleothems produced, in particular, by Mann et al. (2008) and Büntgen et al. (2011). Their production of data is thus based on complementary historical sources and in particular records of droughts and floods, surveys on the surface of lakes, or sandstorms, which are known to be strongly correlated with precipitation levels. In the end, these series make the adequate capture of the alternation of periods of drought and humidity over the period studied.

The used migration data have already been described in the existing literature and in particular by Pei and Zhang (2014) and Pei, Lee, and Zhang (2017). These data come from the chronological tables of the Chinese Migration History, which is a renowned source on the history of historical migrations in China (Ge et al., 1997). We used 928 records of the migration of nomadic minorities and focus on the series of nomadic migratory events China that are produced at a decadal frequency. However, considering the relative small size of decadal frequency data, we also use yearly interpolated data in line with previous literature.

\subsection{Methodology}

We assume an autoregressive (AR) structure to deal with the autocorrelation issues of our model contrary to previous literature that assumes a linear model with deterministic trends. Our linear estimates (available upon request) reveal that previous linear models with trends exhibit low-quality residuals with the remaining autocorrelation and heteroskedasticity.

Linear AR estimations for yearly $(\mathrm{AR}(2)$ is optimal) and decadal (AR(1) is optimal) series lead to similar results (available upon request): only precipitations significantly affect migrations, but temperatures have no effect on migration flows. The sign is negative and confirms the previous results of the literature, considering ordinary least squares regressions with deterministic trends: low precipitations increase the number of migrations from the North to the South of China.

We perform a simple regime AR switching model to go beyond previous literature (Teräsvirta et al., 2010). This model is piecewise linear, and the variable $s$ is generally assumed to be continuous and stationary. When $\mathrm{r}=1$, the model becomes linear again on the overall sample.

$$
\begin{aligned}
& y_{t}=\sum_{j=1}^{r}\left(\beta_{j}^{\prime} z_{t}+\epsilon_{j t}\right) I\left(c_{j-1}<s_{t}<c_{j}\right) \\
& s_{t} \text { is a observed transition variable, } c_{0}, c_{0}, c_{r} \text { are threshold parameters } \\
& \beta_{j}=\left(\beta_{0 j}, \beta_{1 j}, \beta_{m j}\right)^{\prime} \\
& \beta_{i} \neq \beta_{j} \text { for } i \\
& j=1, \ldots, r \text { and } \epsilon_{j t}=\sigma \epsilon_{j t}
\end{aligned}
$$

This methodology enables us to further examine the average linear effect identified between climate and migrations. Threshold models outline regimes and indicate the subperiods that are truly concerned by a causal effect of climate 
on migrations and society disturbances, such as conflicts. Previous literature has explained that migration flows likely generate conflicts and battles in the South China.

\section{Switching model results}

\subsection{Yearly interpolated data}

The results of the discrete threshold model estimates (Table 3) are interesting and shed new light on the relationship between climate and nomadic migration in imperial China. After the number of thresholds estimated for our model are tested (Table 4), which reveals three thresholds (therefore four distinct regimes), we estimate the discrete threshold model over our study period by using the precipitation variable as the transition, that is, one for which the dynamics likely differ from regimes where the explanatory variables have heterogeneous effects on the dependent variable. When rainfall is low and increases soil aridity, especially in Northern China, where mainly nomads originally live, the number of migratory events tends to increase. Precipitation only significantly affects migrations in the first regime (only 326 observations for an estimated negative precipitation threshold) and is therefore the major determinant of migration.

When the precipitation level is relatively in line with its average or significant (high positive anomalies from a threshold of 0.15 in the second regime), this climatic factor no longer appears as a determinant of migration. In addition, when rainfall is low, and drought patterns likely emerge, temperature anomalies, which were insignificant in previous studies, can positively influence migration events. This effect can be explained by the periods of heat concomitant with those of drought degrading the living conditions of the nomadic populations, thereby pushing them to the exodus.

When linear empirical methodologies are used, this regime where the two factors jointly have an influence, migration cannot be identified; on the contrary, the discrete threshold model adopted here allows us to highlight the regimes for which climatic factors can be responsible for migration and not to overestimate its scope as a historical explanatory factor for the entire period, which over time, is not uniform.

Figure 1 demonstrates the estimated values of the thresholds corresponding to the different regimes in the historical perspective. We draw a threshold $\mathrm{T}$ to identify the first regime, for which the coefficients of the climatic variables are significant on the historical precipitation series (corresponding to our transition/threshold variable). Periods 300 to 550, 1050 to 1300 , and 1600 to 1700 (to a lesser extent) correspond to periods when the model is in the first regime. During these periods (approximately $1 / 6$ of the period), climatic factors significantly affect the migratory flows.

The importance of the precipitation effect on migration has probably been slightly overestimated (on average) in previous studies, indicating that it was significant for the entire period. On the contrary, the role of temperature anoma- 
lies (cooling or probably here periods of warming associated with droughts) has been underestimated. In the end, the joint role of climatic anomalies has been an important determinant of migratory movements over several periods.

However, this response by nomads in terms of adaptation to climate change has consequences. Pei et al. (2019) showed that these movements are probably the source of many interpersonal conflicts initiated by the nomads and to which the "agriculturalists" of the South responded with defense strategies. Mass migrations to already occupied territories likely generate tensions, violence, and wars.

Similar to Pei et al. (2019), we apply a Granger causality test to the overall sample to identify potential causal relationships among climate, migration flows, and battle frequency. Considering the linear causality tests over the complete sample, evidence shows that precipitations cause migrations, and battles result in migrations. By contrast, temperatures do not cause migrations.

We now perform Granger causality tests but on the subperiods considering our previous threshold model estimates. We use periods 300-500 and 1050-1300 as detected by our threshold model (Figure 1). First, we implement a causality test between precipitation and migratory movements. Second, we analyze the possible causality between migratory movements and conflicts. The usual information criteria (AIC, SIC) are contradictory as for the optimal number of lags to be retained; hence, we consider AIC and SIC and exhaustively present all the results. When SIC converge to AIC, we report the parsimonious lag in the "SIC" column.

When we consider the subperiods identified by the estimation of our threshold model, temperatures have likely played a significant role during special times. Over the 300-500 period, precipitations and temperatures have effects on migration. Thus, a unidirectional link from precipitations to migrations is active during the total period. However, the link between temperatures and migrations is only active during the $300-500$ period but not otherwise.

The causal link from battles to migrations (all sample) still exists over $300-500$ but disappears over 300-500. On the contrary, migrations seem to cause battles over 1050-1300 only. The direct tests from precipitations and temperatures to battles (available upon request) show significant relationships.

Our tests demonstrate that the causal links over the subperiods identified by our nonlinear model only partially corroborate the following hypothesis: Precipitation causes migrations, which cause conflicts/battles. If the link between precipitation and migration is relatively well established, then whatever the subperiod and the information criterion used, the link between migration and conflicts between "agriculturalists" and "pastoralists" is less clear and does not appear than during the second subperiod studied.

A drawback of linear causality tests is their inability to detect potential nonlinearities in the dynamic dependence structure. Finally, we attempt to check the robustness of these results by performing the nonlinear Granger causality test from Diks and Panchenko (2006). Diks and Panchenko (2005, 2006) proposed the bivariate Diks and Panchenko nonparametric Granger causality test, which is a modified version of the widely used HJ test of Hiemstra and Jones 
Table 1: Estimation of a discrete threshold model

\begin{tabular}{|c|c|c|c|c|}
\hline Regimes & $\begin{array}{l}\text { Precipitations }<-0.469 \\
N=326\end{array}$ & & $\begin{array}{l}\text { Precipitations }<0.155721 \\
\mathrm{~N}=948\end{array}$ & \\
\hline Variables & Coefficient & t-stat & Coefficient & t-stat \\
\hline Constant & $-0.070401^{*}$ & -1.788174 & $0.034346^{* * *}$ & 2.756372 \\
\hline Precipitations & $-0.258385^{* * *}$ & -4.703150 & -0.006468 & -0.204507 \\
\hline Temperatures & $0.041096^{* * *}$ & 3.116277 & 0.000684 & 0.095144 \\
\hline Migration(-1) & $1.856937^{* * *}$ & 84.79567 & $1.931984^{* * *}$ & 104.3295 \\
\hline Migration(-2) & $-0.879420^{* * *}$ & -38.76141 & $-0.946794^{* * *}$ & -48.87981 \\
\hline Migration $(-12)$ & $0.011820^{* * *}$ & 4.000014 & $0.009151^{* * *}$ & 3.301231 \\
\hline Regimes & $\begin{array}{l}\text { Precipitations }<0.410 \\
N=337\end{array}$ & & $\begin{array}{l}\text { Precipitations }>0.410 \\
N=300\end{array}$ & \\
\hline Variables & Coefficient & t-stat & Coefficient & t-stat \\
\hline Constant & $0.049192^{* *}$ & 1.942834 & 0.054056 & 1.413700 \\
\hline Precipitations & -0.014839 & -0.220979 & -0.030787 & -0.642592 \\
\hline Temperatures & -0.019771 & -1.621084 & 0.009703 & 0.517224 \\
\hline Migration(-1) & $1.716194^{* * *}$ & 50.50654 & $1.909292^{* * *}$ & 46.81999 \\
\hline Migration(-2) & $-0.749950 * * *$ & -21.75798 & $-0.919982^{* * *}$ & -21.80111 \\
\hline Migration (-12) & $0.010909^{* *}$ & 2.239927 & 0.002238 & 0.415936 \\
\hline
\end{tabular}

(1994). They mitigated the severe over-rejection rates that characterize the socalled HJ test under the null hypothesis of Granger noncausality between two variables.

The results confirm the existence of causality from precipitations to migrations, at least if the bandwidth is between 1.00 and 2.00 if we avoid the high number of lags selected by the AIC criterion. In the same way, no causality exists between temperatures and migrations. Finally, if a direct and significant link exists between migrations and battles, then it comes from battles to migrations. This effect is in contrast with the causal scheme previously identified in the literature explaining that a large number of migrations induced by climate change lead to increased battles.

$$
[\mathrm{pbth}]
$$

Note: The thresholds have been estimated sequentially ( $\mathrm{S}+1$ versus $\mathrm{S}$ ), the precipitation anomaly variable la variable (t-3) is optimal for an AutoRegressive model. The horizontal $\mathrm{T}$ denotes the estimated threshold of the first regime $(-0.469 \mathrm{~mm})$, T2 denotes the estimated threshold of the second regime and T3 enables us to separate the third and the fourth regimes.

Note : the values are represented as as F-Stat (P-values); * denotes that $\mathrm{H} 0$ has been rejected at $10 \%$; number of lags has been chosen by using AIC and SIC information criteria, since the number of lags can change according to the initial possible set of lags, SIC can convergence to AIC when the potential number of lags is high, so we decide to use the parsimonious number of lags in the SIC column. 
Figure 1: Precipitations anomaly dynamics and comparison with estimated thresholds (yearly data)

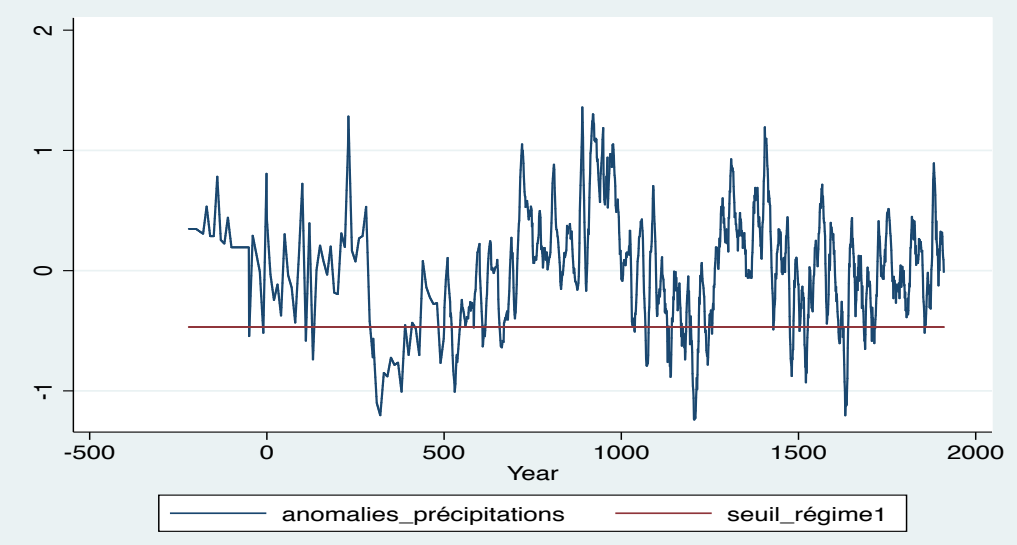


Table 2: Bai and Perron test

\begin{tabular}{llll}
\hline Thresholds & Scaled Critical & & \\
\hline Threshold Test & F-statistic & F-statistic Value & \\
0 vs. 1 & $4.429136^{*}$ & 26.57482 & 20.08 \\
1 vs. 2 & $5.990436^{*}$ & 35.94262 & 22.11 \\
2 vs. 3 & $4.759571^{*}$ & 28.55743 & 23.04 \\
3 vs. 4 & 2.181079 & 13.08647 & 23.77 \\
\hline
\end{tabular}

Table 3: Linear Granger causality tests (all sample)

\begin{tabular}{lll}
\hline & All sample & \\
\hline Hypothesis/info criterion & AIC & SIC (or parsimonious) \\
Precipitations do not cause Migrations & $4.16^{*}(0.01)$ & $1.59^{*}(0.09)$ \\
Migrations do not cause Precipitations & $1.09(0.32)$ & $0.76(0.70)$ \\
Temperatures do not cause Migrations & $0.09(1.00)$ & $0.14(0.87)$ \\
Migrations do not cause Temperatures & $0.52(0.90)$ & $0.14(0.87)$ \\
Migrations do not cause Battles & $0.20(0.99)$ & $0.31(0.74)$ \\
Battles do not cause Migrations & $3.11^{*}(0.00)$ & $0,76(0.46)$ \\
\hline
\end{tabular}

Table 4: Linear Granger causality tests (sub-periods)

\begin{tabular}{lllll}
\hline & $300-500$ period & \multicolumn{3}{l}{$1050-1300$ period } \\
\hline Hypothesis/info criterion & AIC & SIC & AIC & SIC \\
Precipitations do not cause Migrations & $1.66^{*}(0.07)$ & $2.41^{*}(0.09)$ & $0.89(0.55)$ & $10.48^{*}(0.00)$ \\
Migrations do not cause Precipitations & $0.58(0.87)$ & $0.32(0.72)$ & $0.80(0.65)$ & $2.17(0.14)$ \\
Temperatures do not cause Migrations & $1.60^{*}(0.09)$ & $1.60^{*}(0.09)$ & $0.11(0.99)$ & $0.03(0.97)$ \\
Migrations do not cause Temperatures & $3.74^{*}(0.00)$ & $3.74^{*}(0.00)$ & $0.57(0.86)$ & $0.89(0.41)$ \\
Migrations do not cause Battles & $0.13(0.99)$ & $0.71(0.49)$ & $3.38^{*}(0.00)$ & $0.45(0.64)$ \\
Battles do not cause Migrations & $2.26^{*}(0.01)$ & $2.27(0.11)$ & $1.38(0.17)$ & $0.90(0.41)$ \\
\hline
\end{tabular}


Table 5: Nonlinear Granger causality tests (sub-periods)

\begin{tabular}{lllll}
\hline bandwith & 1.00 & 1.00 & 2.00 & 2.00 \\
\hline Hypothesis/info criterion & AIC & SIC & AIC & SIC \\
Precipitations do not cause Migrations & $1.85^{*}(0.03)$ & $1.87^{*}(0.03)$ & $2.24^{*}(0.01)$ & $2.26^{*}(0.01)$ \\
Migrations do not cause Precipitations & $2.14^{*}(0.02)$ & $0.89(0.19)$ & $1.20(0.12)$ & $0.19(0.42)$ \\
Temperatures do not cause Migrations & $0.50(0.31)$ & $0.52(0.30)$ & $0.26(0.40)$ & $0.17(0.43)$ \\
Migrations do not cause Temperatures & $0.98(0.16)$ & $0.26(0.40)$ & $0.05(0.48)$ & $0.22(0.41)$ \\
Migrations do not cause Battles & $-0.64(0.73)$ & $-0.07(0.53)$ & $-1.78(0.96)$ & $0.33(0.37)$ \\
Battles do not cause Migrations & $1.77^{*}(0.04)$ & $1.59^{*}(0.06)$ & $1.36^{*}(0.09)$ & $0.48(0.31)$ \\
\hline
\end{tabular}

Note : the values are represented as as F-Stat (P-values) ; ${ }^{*}$ denotes that H0 has been rejected at 10

Note : the values are represented as as F-Stat (P-values) ; ${ }^{*}$ denotes that $\mathrm{H} 0$ has been rejected at 10

\section{Robustness tests: Time varying copula results}

\subsection{Yearly frequency}

We check the robustness of the previous results by conducting time-varying copula; see the recent paper by Damette and Goutte (2020) for further details about the methodology and the first application to climate issues. The copula methodology is interesting because it enables us to investigate the dependence of the statistical distribution of two variables. Meanwhile, time-varying analysis enables us to classify periods with zero, negative, or positive dependence and study temporal heterogeneities. Specifically, the dependence is likely to be highly significant in certain periods and insignificant in other ones.

Figures 3 and 4 show that the dependence between precipitations and nomadic migrations is strongly negative between 300 and 400 and around 1,200 and 1,500 (in a lesser extent), considering normal and student distributions. Thus, both variables are linked in the reverse sense. During these periods, droughts have increased migrations and lead to people displacements from the North to the South of China. These results are partially in line with previous threshold regression results that identify a regime switching with a negative effect of climate on migrations between 300 and 550 and 1050 and 1300. The subperiod $300-400$ is embedded in $300-550$, but $1200-1500$ is quite different from the 1050-1300 period previously identified.

By contrast, copula analysis reveals that in the beginning of the 900s and the 1400s, the relationship between precipitations and migrations is positive. Abnormal rainfall likely increases nomadic migration over this period. This possible relationship is invisible with usual regressions. 


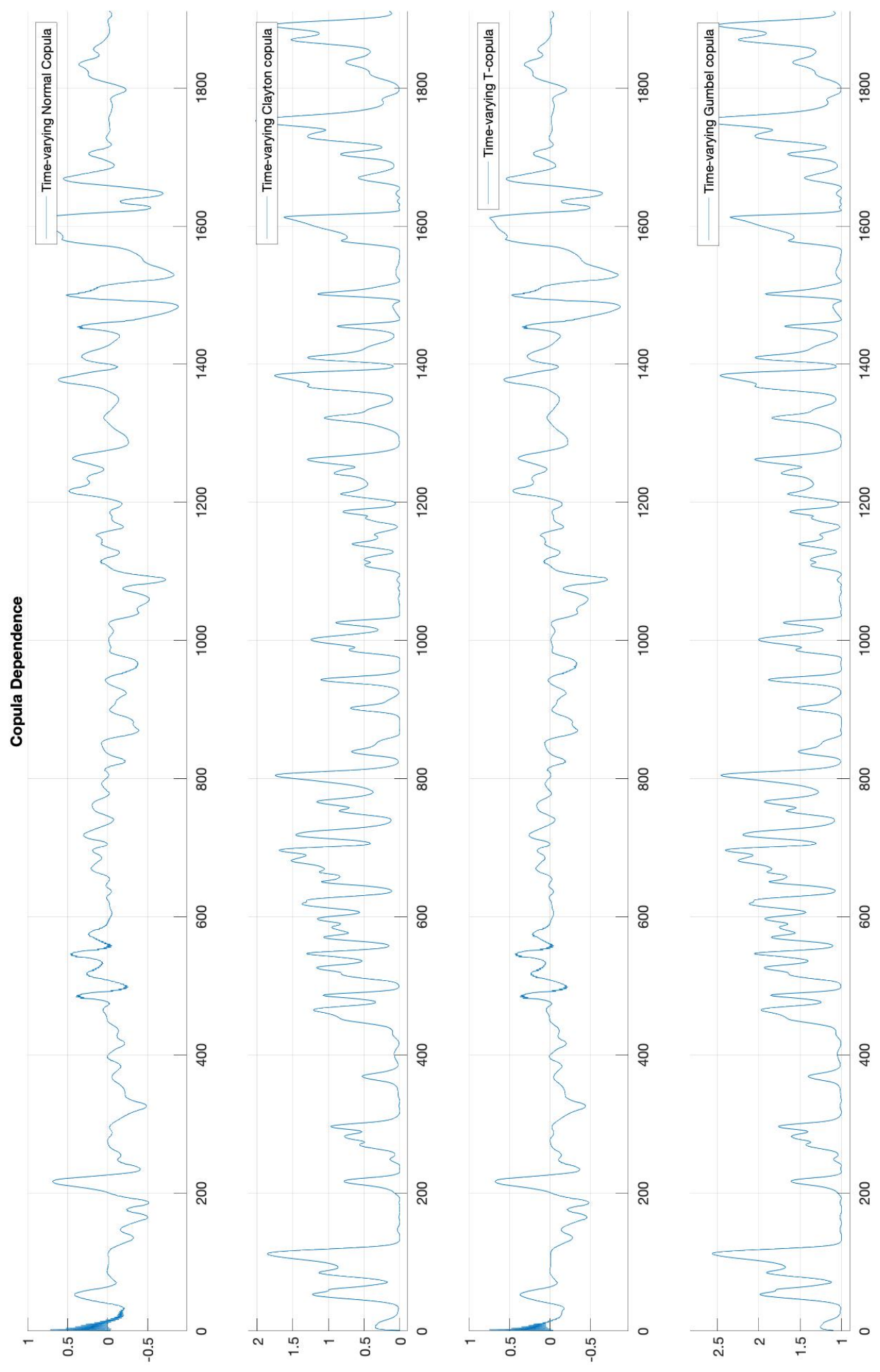

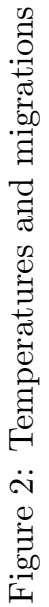




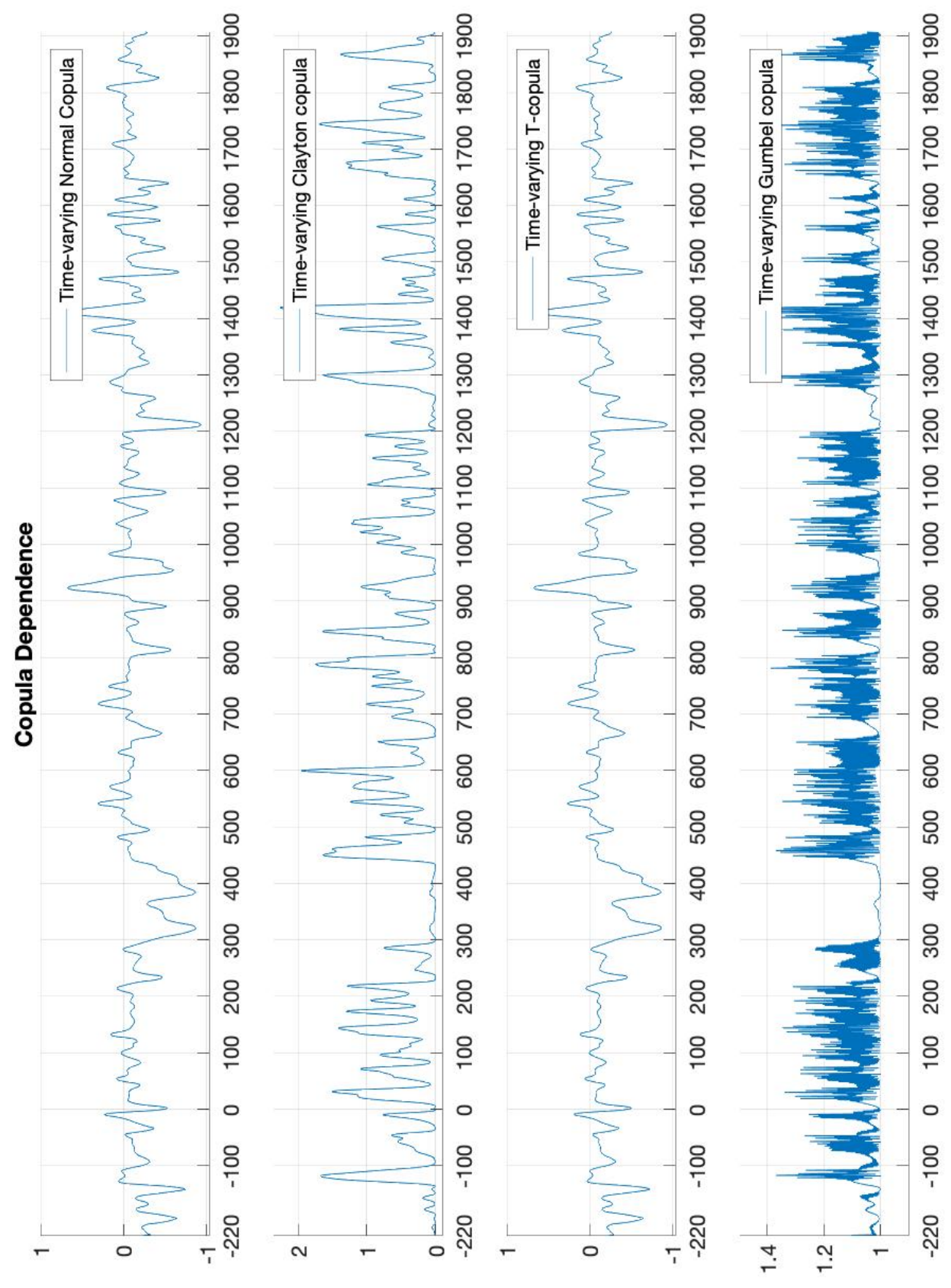

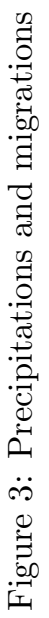




\subsection{Decadal frequency}

Figure 5 (time-varying normal copula and T-copula) demonstrates that the copula analysis reveals a negative dependence between precipitations and migrations. The coefficient turns to be negative around $400(375-450)$ and in a lesser extent between 1200 and 1300 (a slight decrease). Periods of drought or insufficient precipitations have likely provoked people from North China to migrate in the South, thereby increasing migrations.

The link between temperatures and the number of battles (Figure 6) is also negative. This phenomenon occurs because the cooling periods associated to drought periods (the dependence between temperatures and precipitations is positive and thus cooling and drought periods coexist) have increased migrations and then the battles in South China.

However, the link between battles and migrations (Figure 7), even though positive (increased migration flows are associated with an increasing number of battles), is relatively stable over time regardless of the distribution considered.

We also identify a direct positive association between precipitations and the number of battles, especially between 400 and 600 . Consequently, the increasing migrations generated by potential droughts over $375-450$ are probably at the origin of a positive link between precipitations and the number of battles over $400-600$.
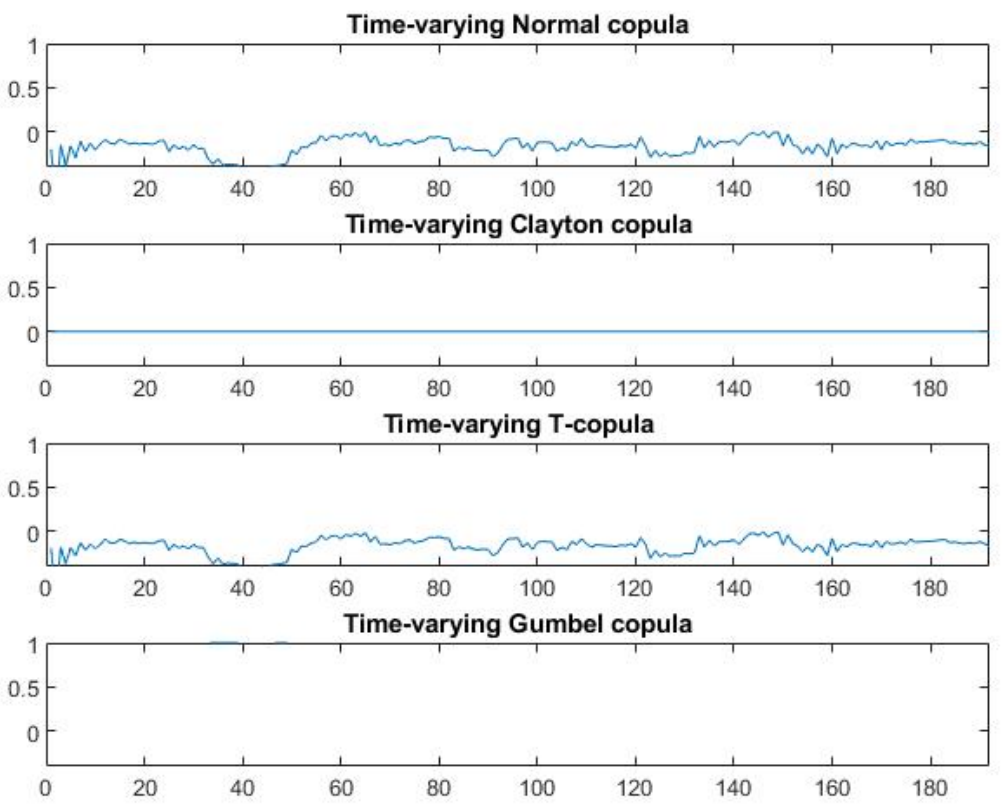

Figure 4: Precipitations and migrations 

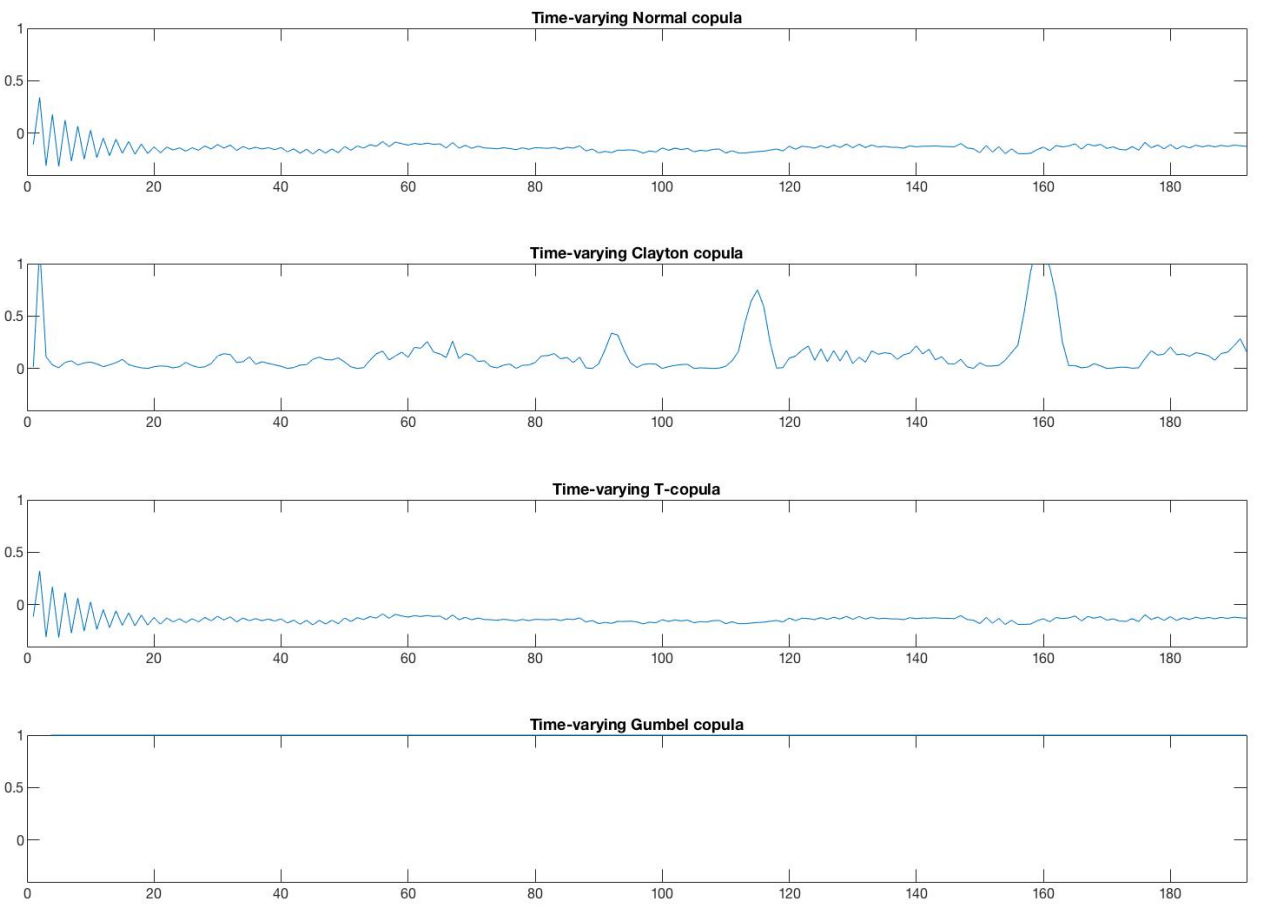

Figure 5: Temperatures and migrations 

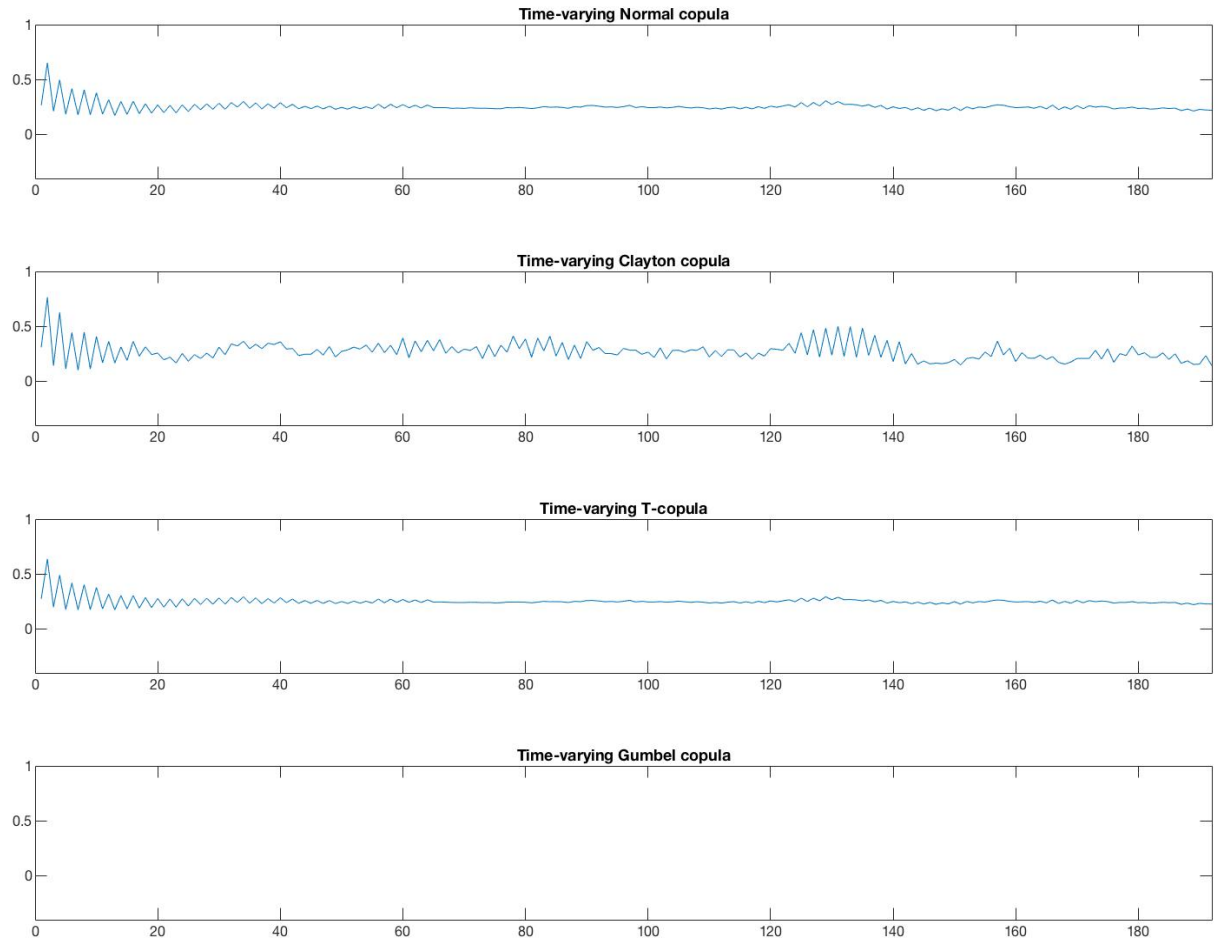

Figure 6: Battles and migrations 


\section{Discussion}

Previous results have confirmed the significance of climate change in driving nomadic migration in the vein of existing studies, for instance Bai and Kung (2011), Chen (2015), Pei and Zhang (2014), and Pei et al. (2016). In these studies, climate change is only interpreted in a linear manner, such as by using correlation, linear regression, and linear Granger causality. These existing works mainly aim to complete the tasks to verify the climate change-nomadic migration linkage in the past. Our work has developed the existing knowledge on the roles of climate change and nomadic migration by using nonlinear methods.

1. Climatic effects via non-linear patterns Our threshold model results demonstrate that the coefficient associated to precipitations is significant only during the dry phase (precipitation inferior to 0.469) but not in the three other phases, which are much wetter. During a dry period, the push of climate change is strong enough to make nomads migrate mainly southward into the agrarian region of China. Figure 1 presents that those periods of precipitation below 0.469 overlap with Sixteen Kingdoms to Northern and Southern dynasties (300-590 AD), Yuan Dynasty (1270-1368 AD), and Qing Dynasty (1644-1911 AD), when nomads occupied the heartland of China (Ledyard, 1983; Zhang et al., 2015). In the real history, Southern China was affected by the southward nomadic migration.

With the help of the threshold model, we can also identify a new type of effect from temperature change on migrations. Temperature dynamics in previous literature (Pei et al. (2018) or Pei and Zhang (2014)) were only examined within a quite long duration. However, our model, as a first attempt, divides the whole history of imperial China into four different phases according to the precipitation level. The temperatures present positive effects on migrations during the dry period (precipitation inferior to 0.469 ), indicating that increased temperature in nomadic regions can make local environment further drier, particularly in North China. Although precipitations mainly dominate the bioproductivity in North China (Sternberg, 2008), temperatures should not be neglected. A unique role of temperatures during the dry phase has been identified together with drought at such a new time duration.

Overall, such seemingly repeated practice by nonlinear methods still reminds us to closely examine nomads and the nomadic society from the view of climate change and other types of environmental changes. In the current academia, the explanation of the social past from the environmental change is still insufficient as a consequence of avoiding the trap of environmental determinism. As a nomadic society, we have scrutinized the climate change-nomadic migration linkage by using linear and nonlinear methods. Furthermore, the findings of the study on the climate change-nomadic migration linkage in historical China can be applicable to interpret the migration of other nomadic tribes across the whole Eurasian continent in human history, because the nomads in China had a close contact with other nomadic tribes across Eurasia. 
2. Resilience of nomads: Not only migration southward In our paper, if the extent of climate change is not serious enough to reach to a critical point (such as 0.469 in this study), then nomadic tribes do not necessarily migrate (Table 1 ). In terms of nomadic tribes, migration is regarded as the only immediate way to adapt to climate change (Fang and Liu, 1992; Zhang et al., 2015). Therefore, the findings of our threshold model help us review the resilience of the nomadic society under climate change.

The migration events used in the study are those that can threaten territorial security and farming livelihoods in imperial China and thus are carefully recorded in historical documents (Ge et al., 1997). According to our results, if climatic conditions are not enough disastrous, then migration, particularly southerly migration, will not be necessarily chosen by nomads. If nomads migrate southward, then they will risk the potential conflicts with farmers living in the south. Only when the push of drought is strong enough can the southern agrarian China be attractive to nomads even under the risks of conflicts with the farmers in the south.

Although migration is regarded as an effective solution, the results remind us to pay attention to other types of adaptive and resilient choices by nomads. Even though we still consider migration as the resilient choice by nomads, they can migrate northward or move along the latitude line, which may not be well recorded in Chinese historical documents. Nomadic tribes did have developed other means of resilient choices, particularly in recent centuries, when the Jurchen people flourished in Northeast China as an example. In the eye of farmers, the Jurchen people were completely nomads. In Northeast China, the harsh climate forced them to develop living methods. Therefore, the Jurchen people developed the semi-husbandry and semi-agricultural societies (Mote, 1999). The resilient methods adopted by nomads to relieve climatic impacts should be examined in the future.

3. Scale issue in climate change and social response Another contribution of this study is the empirical evidence on the importance of scale in the climate change-nomadic migration linkage. In previous studies, the narrowed down scale in space has been proven to lead to different findings on the basis of the migration studies in historical China (Pei et al., 2019). However, no evidence is available to reveal the changes of temporal duration thereby affecting the results.

In this study, we have divided the whole study period into different phases according to precipitation level. In a shortened period of four climatic phases, the temperature presents a different result from past studies. Furthermore, the linkage between climate change and nomadic migration is not always effective in all those climatic phases. Therefore, as the fundamental issue of methodology in geography, the scale in time and space must be given enough attention in the future. If the study scale is changed, a new understanding should be provided to interpret and explain the long-run dynamics of the series and human history (Chaplin, 2015). Particularly, if we narrow the scale and specify the target, factors apart from the effects of climate change (i.e., resilience of nomads) should 
be considered and perhaps given more explanatory weight than at a large scale in space and time (Gibson et al., 2000).

\section{Conclusion}

The present study has empirically revisited the climate change-nomadic migration linkage in a statistical approach by using some recent nonlinear econometric methods. This new batch of results still has shown the importance of climate change on pushing nomads to migrate southward. However, except during the extremely dry period, nomads may have choices other than southward migration. Such results enlighten us about the need to conduct further studies on the resilience of nomads under different climatic conditions in the future.

Drought can result in other influential consequences with the increase in temperature, as shown in our study. The current level of climate change has never been experienced in the past millennia. Warming may reduce the precipitation level and water resource in Central Asia (Sorg et al., 2012). Therefore, we should be aware of these potential effects if the current warming trend still continues. Arid and semi-arid regions can be strikingly affected, thereby leading to the potential increase in climate-migration or other social and political consequences.

\section{References}

Akaike, H., (1974). A new look at the statistical model identification. IEEE Trans. Automat. Contr. 19, 716-723.

Allen, R.C., Bassino, J.-P., Ma, D., Moll-Murata, C., Zanden, J.L.v., (2011). Wages, prices, and living standards in China, 1738-1925: in comparison with Europe, Japan, and India. Econ. Hist. Rev. 64, 8-38.

Bai, Y., Kung, J.K.-s., (2011). Climate shocks and sino-nomadic conflict. Rev. Econ. Stat. 93, 970-981.

Barker, R., 2012. The origin and spread of early-ripening champa rice: it's impact on song dynasty China. Rice 4, 9079.

Büntgen, U., Tegel, W., Nicolussi, K., McCormick, M., Frank, D., Trouet, V., Kaplan, J.O., Herzig, F., Heussner, K.-U., Wanner, H., Luterbacher, J., Esper, J., (2011). 2500 years of European climate variability and human susceptibility. Science 331, 578-582.

Büntgen, U., Di Cosmo, N. (2016) Climatic and environmental aspects of the Mongol withdrawal from Hungary in 1242 CE. Scientific Reports 6, 25606.

Campbell, C., Lee, J., (2001). Free and unfree labor in Qing China Emigration and escape among the bannermen of northeast China, 1789-1909. Hist. Fam. 6, 455-476. Campbell, C., Lee, J.Z., Elliott, M., 2002. Identity construction and reconstruction: naming and Manchu ethnicity in northeast China, 1749-1909. Hist. Methods 35, 101-115. 
Chaplin, J.E. (2015). Ogres and Omnivores: Early American Historians and Climate History. The William and Mary Quarterly 72, 25-32.

Damette O., Goutte S. (2020). Beyond climate and conflict relationships: new evidence from copula analysis. BETA Working Paper, 2020-19.

Di Cosmo, N. (2002) Ancient China and its enemies : the rise of nomadic power in East Asian history. Cambridge University Press, Cambridge.

Chen, Q. (2015) Climate shocks, dynastic cycles and nomadic conquests: evidence from historical China. Oxford Economic Papers 67, 185-204.

Dong, G., Liu, F., Chen, F., (2017). Environmental and technological effects on ancient social evolution at different spatial scales. Sci. China Earth Sci. 60, 2067-2077.

Fang, J.Q., Liu, G., (1992). Relationship between climatic change and the nomadic southward migrations in eastern Asia during historical times. Climatic Change 22, 151-168.

Friston, K.J., Bastos, A.M., Oswal, A., Wijk, B.v., Richter, C., Litvak, V., (2014). Granger causality revisited. Neuroimage 101, 796-808.

Ge, J., Wu, S., Cao, S., (1997). The History of Migration in China. Fujian People's Publishing House, Fu Jian.

Gibson, C.C., Ostrom, E., Ahn, T.K. (2000). The concept of scale and the human dimensions of global change: a survey. Ecological Economics 32, 217239.

Granger C.W.J. (1969). Investigating Causal Relations by Econometric Models and Cross-spectral Methods. Econometrica, 37, 424-438.

Halsall, G. (2007) Barbarian migrations and the Roman West, 376-568. Cambridge University Press, Cambridge.

Hsiang, S.M., Burke, M., Miguel, E. (2013) Quantifying the Influence of Climate on Human Conflict. Science 341, 1235367.

Imber, C. (2002) The Ottoman Empire, 1300-1650 : the structure of power. Palgrave Macmillan, Basingstoke, Hampshire ; New York, N.Y.

Ledyard, G. (1983). Yin and Yang in the China-Manchuria-Korea Triangle. University of California Press, Berkeley.

Lee, H.F., Zhang, D.D., Brecke, P., Fei, J., (2013). Positive correlation between the north atlantic oscillation and violent conflicts in Europe. Clim. Res. 56, $1-10$.

Lee, H.F., Zhang, D.D., Pei, Q., Fei, J., (2016). Downscaling and disaggregating NAO- conflict nexus in pre-industrial Europe. Chin. Geogr. Sci. 26, 609-622.

Lee, H.F., Zhang, D.D., Pei, Q., Jia, X., Yue, R.P.H., (2017). Quantitative analysis of the impact of droughts and floods on internal wars in China over the last 500 years. Sci. China Earth Sci. 60, 2078-2088. 
Lee, J., (1978). Migration and expansion in Chinese history. In: McNeill, W.H., Adams, R.S. (Eds.), Human Migration: Patterns and Policies. Indiana University Press, Bloomington, Ind, pp. 20-47.

McNeall, D., Halloran, P.R., Good, P., Betts, R.A. (2011) Analyzing abrupt and nonlinear climate changes and their impacts. WIREs Climate Change 2, 663-686.

Mote, F.W. (1999). Imperial China 900-1800. Harvard University Press, Cambridge, Mass.

Parker, G., (2013). Global Crisis: War, Climate Change and Catastrophe in the Seventeenth Century. Yale University Press, New Haven.

Pei, Q., Zhang, D.D. (2014). Long-term relationship between climate change and nomadic migration in historical China. Ecology and Society. 19, 68.

Pei, Q., Zhang, D.D., Li, G., Lee, H.F., (2015a). Climate change and the macroeconomic structure in pre-industrial Europe: new evidence from wavelet analysis. PLoS One 10, e0126480.

Pei, Q., Zhang, D.D., Li, G., Winterhalder, B., Lee, H.F., (2015b). Epidemics in Ming and Qing China: impacts of changes of climate and economic well-being. Soc. Sci. Med., 136 (137), 73-80.

Pei, Q., Zhang, D.D., Lee, H.F. (2016a) Contextualizing human migration in different agro-ecological zones in ancient China. Quaternary International 426, 65-74.

Pei, Q., Zhang, D.D., Li, G., Forêt, P., Lee, H.F. (2016b). Temperature and precipitation effects on agrarian economy in late imperial China. Environ. Res. Lett. 11, 64008-64016.

Pei, Q., (2017). Migration for survival under natural disasters: a reluctant and passive choice for agriculturalists in historical China. Sci. China Earth Sci. 60, 2089-2096.

Pei, Q., Lee, H.F., Zhang, D.D., Fei, J. (2018). Climate change, state capacity and nomad-agriculturalist conflicts in Chinese history. Quaternary International, https://doi.org/10.1016/j.quaint.2018.1010.1022.

Pei, Q., Nowak, Z., Li, G., Xu, C., Chan, W.K. (2019). The Strange Flight of the Peacock: Farmers' atypical northwesterly migration from central China, 200BC-1400AD. Annals of the Association of American Geographers 109, 15831596 .

Rosenberg, A. (2008) Philosophy of social science, 3rd ed. Westview Press, Boulder, CO.

Sorg, A., Bolch, T., Stoffel, M., Solomina, O., Beniston, M. (2012). Climate change impacts on glaciers and runoff in Tien Shan (Central Asia). Nature Climate Change 2, 725-731.

Sternberg, T. (2008). Environmental challenges in Mongolia's dryland pastoral landscape. Journal of Arid Environments 72, 1294-1304. 
Yang, B., Braeuning, A., Johnson, K.R., Yafeng, S. (2002). General characteristics of temperature variation in China during the last two millennia. Geophys. Res. Lett. 29, 1324.

Yi, L., Yu, H., Ge, J., Lai, Z., Xu, X., Qin, L., Peng, S. (2012). Reconstructions of annual summer precipitation and temperature in north-central China since $1470 \mathrm{AD}$ based on drought/flood index and tree-ring records. Climatic Change 110, 469-498.

Yin, J., Su, Y., Fang, X. (2015). Relationships between temperature change and grain harvest fluctuations in China from $210 \mathrm{BC}$ to $1910 \mathrm{AD}$. Quat. Int. $355,153-163$.

Zhang, D.D., Pei, Q., Lee, H.F., Zhang, J., Chang, C.Q., Li, B., Li, J., Zhang, X. (2015). The pulse of imperial China: a quantitative analysis of long-term geopolitical and climate cycles. Global Ecology and Biogeography 24, 87-96. 